\title{
A Wolf in Sheep's Clothing: Keratosis Obturans Causing Facial Nerve Palsy - A Case Report with Review of the Literature
}

\author{
Case Report $>$ Anup Singh (D, Mubashshirul Haq (D), Kumud Kumar Handa (D) \\ Department of Otolaryngology and Head \& Neck Surgery, Medanta-The Medicity, Gurugram, India
}

Abstract

ORCID IDs of the authors: A.S. 0000-0001-9893-7106; M.H. 0000-0001-7984-1125; K.K.H. 0000-0002-1888-2879.

Cite this article as: Singh A, Haq M, Handa KK. A Wolf in Sheep's Clothing: Keratosis Obturans Causing Facial Nerve Palsy - A Case Report with Review of the Literature. Turk Arch Otorhinolaryngol 2019; 57(2): 102-4.

\section{Corresponding Author:} Anup Singh; anoop.aiims1@gmail.com

Received Date: 14.02.2019

Accepted Date: 05.05.2019 DOl: 10.5152/ta0.2019.4194

\section{(c) (i)}

Content of this journal is licensed under a Creative Commons Attribution 4.0 International License. Available online at www.turkarchotolaryngol.net
Keratosis obturans is a benign disease caused by layered impaction of wax within the external auditory canal. It presents with acute onset of pain and ear blockade. The current report discusses a 24-year-old male patient with recurrent unilateral keratosis obturans associated with facial canal erosion and resulting in facial palsy. A detailed review of the literature is presented. Keratosis obturans can behave aggressively, resulting in significant erosion of the bone and intratemporal structural damage and complications. Timely intervention is vital.

Keywords: Keratosis, ear canal, bone resorption, facial paralysis

\section{Introduction}

Formation of wax in the external auditory canal $(\mathrm{EAC})$ is a physiologic phenomenon. Keratosis obturans (KO) refers to the abnormal accumulation of keratin debris, forming wax plugs in the EAC, leading to its symptomatic presentation. A case with characteristics of $\mathrm{KO}$ was first described by Toynbee (1) in 1850. The names KO and EAC cholesteatoma (EACC) were used synonymously until 1980, when Piepergerdes et al. (2) reviewed the literature and analyzed his six cases to propose that $\mathrm{KO}$ and $\mathrm{EACC}$ are two clinicopathologically distinct entities.

Keratosis obturans resulting in facial nerve palsy has been rarely reported in literature. We report a young male with keratosis obturans, presenting with a short period of symptomatology and associated with complete facial nerve palsy. A pertinent thorough literature review is presented.

\section{Case Presentation}

A 24-year-old male presented to us with complaints of a recurrent history of impacted wax in the left ear and facial weakness on the left side for ten days. The patient also complained of severe left ear pain, aural fullness and impairment of hearing. At the time of presentation, the patient was taking oral steroid in tapering dose as advised by another clinician, but there had been no improvement in facial weakness.

Otoscopic examination of the left ear revealed impacted wax with keratinous debris in the EAC. There was House-Brackmann grade VI lower motor neuron type facial palsy on the left side. His right ear was normal. Rinne's test was negative on the left side and Weber's test showed lateralization towards the left side.

A high-resolution computed tomography was performed, which showed homogenous soft tissue density in the left EAC with erosion of posterior EAC wall (Figure 1) and vertical segment of facial canal (Figure 2). The middle ear and the mastoid cell system were within normal limits. Pure tone audiometry showed mild conductive hearing loss on the left side and normal hearing on the right side.

With the above clinico-radiological picture, a diagnosis of $\mathrm{KO}$ involving the left ear was made. An 


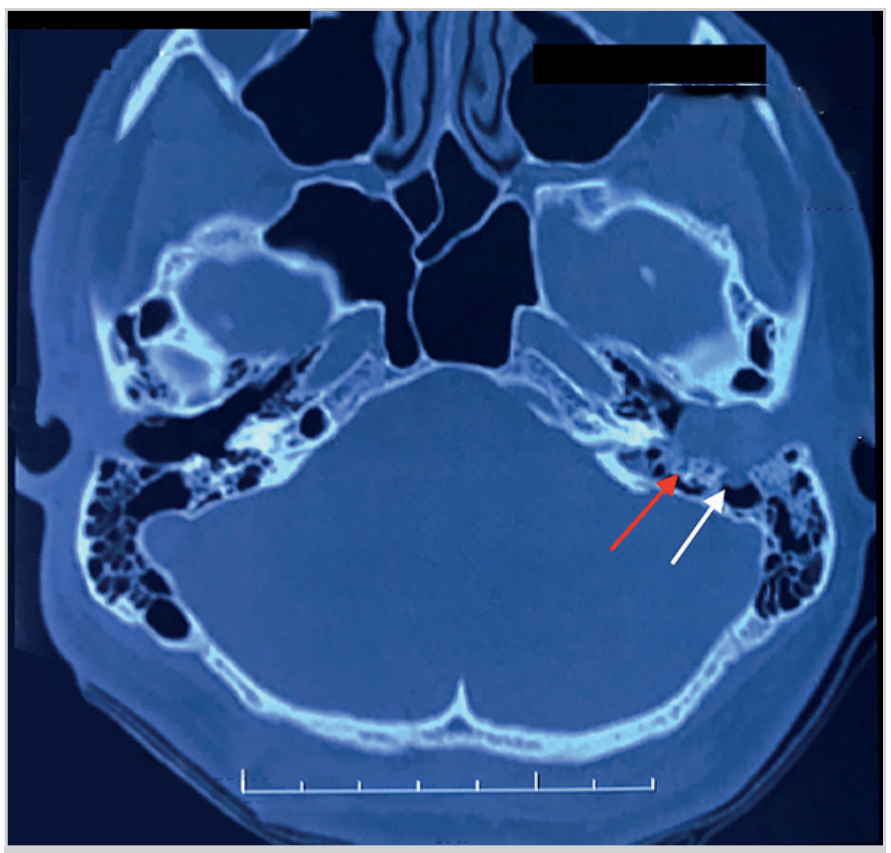

Figure 1. High resolution computed tomography of temporal bone. Axial section at external auditory canal (EAC) level showing impacted soft tissue density with erosion of posterior the EAC wall (white arrow) and erosion of the anterior wall of the vertical facial canal (red arrow)

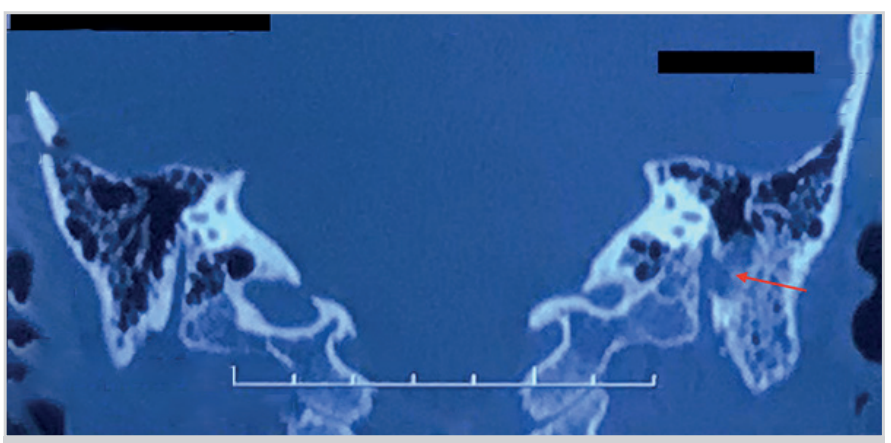

Figure 2. High resolution computed tomography of temporal bone. Coronal section at vertical facial nerve level showing erosion involving the mid vertical part of the facial canal (red arrow). Middle ear space and mastoid cell system are well preserved

attempt to remove the impacted wax in an outpatient setting could not be tolerated by the patient in view of pain and after discussing with the patient decision was made to remove the wax and further explore under general anesthesia. Examination under microscope revealed impacted keratin debris filling up the canal. The posterior wall of the EAC was eroded with extensive granulations in the posterior half and the inferior part of the bony EAC (Figure 3), extending onto the posterosuperior part of the tympanic membrane. Tympanic membrane was intact but slightly medialized. Middle ear was found to be disease free. A small bony bridge of the lateral part of the posterior wall of the EAC was found intact, which was taken down. The middle and lower $1.5 \mathrm{~cm}$ of the vertical segment of the facial canal was found dehiscent and covered with granulations (Figure 4). Disease clearance and facial nerve decompression was performed around $5 \mathrm{~mm}$ on both sides of the exposed ends, and temporalis fascia graft was used to cover the cavity wall. Postoperatively,

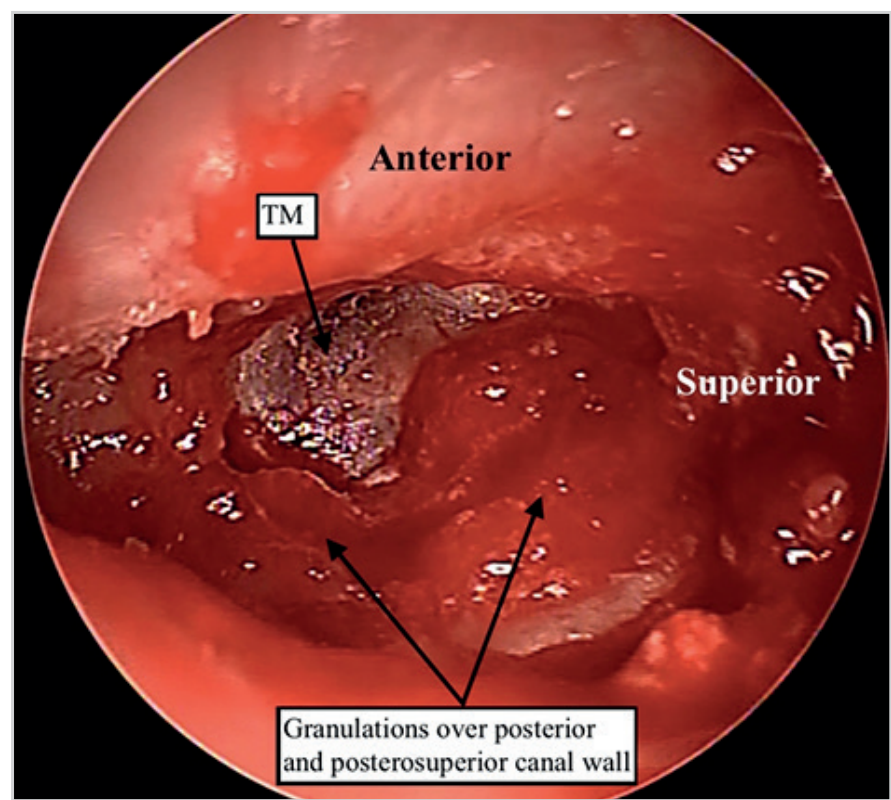

Figure 3. Left ear intraoperative pictures showing the expanded medial external auditory canal (EAC) with extensive granulations involving the posterior and the inferior part of the EAC encroaching onto the posterosuperior tympanic membrane. (Magnification under microscope X6.4)

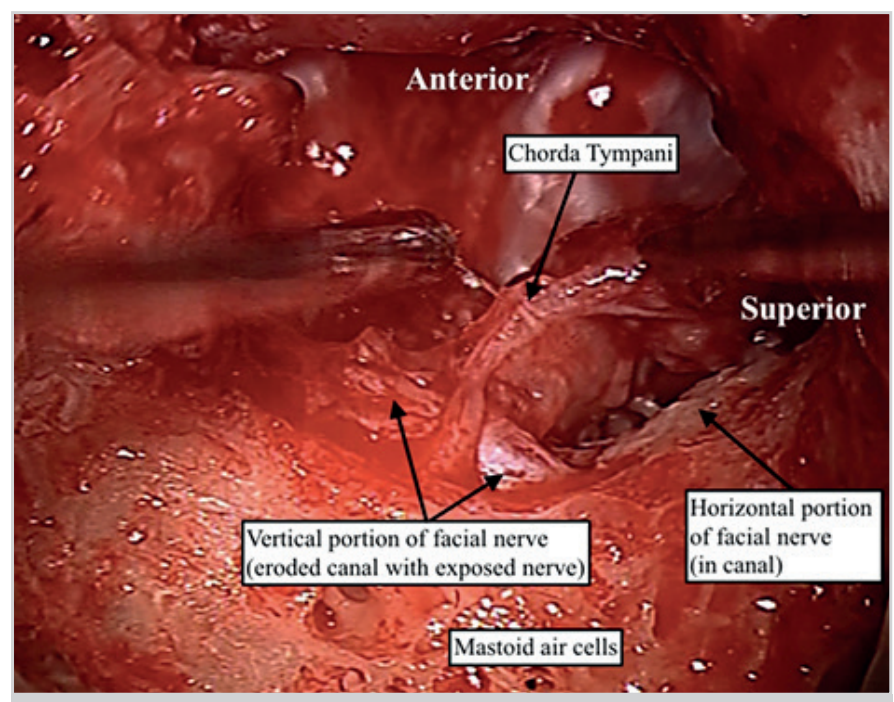

Figure 4. Dehiscent anterior wall of the upper-middle mastoid segment of the facial nerve. (Magnification under microscope X10)

healing was uneventful and bone conduction was normal. Histopathology revealed squamous epithelium with keratinous debris. During a follow-up of six months after surgery, the facial nerve improved from grade VI to grade III. Consent was taken from the patient for the medical photography and publication.

\section{Discussion}

Keratosis obturans has been confused with EACC in the past; however, there are important differences between the two entities, both clinically and pathophysiologically (2). Essentially, the culprit in $\mathrm{KO}$ is the faulty canal skin which sets the ground for the further sequence of events, while in EACC it's the underlying periosteitis/necrotic bone which triggers the reactive changes in the overlying skin. 
The usual presentation with $\mathrm{KO}$ is an acute onset of severe ear pain with ear blockade and hearing loss. There is no ear discharge. The 'ballooning' of the bony EAC causes the annulus and the tympanic membrane to 'stand out in relief' $(3,4)$. Its management may begin with conservative measures, however, severe pain and tightly plugged wax commonly requires general anesthesia for removal. Oftentimes, the underlying inflamed epithelium may recover with local steroid +/- antibiotic ear drops and the normal migration pattern may get restored without needing any further interventions. Some patients, however, may need long term repeated suction cleaning of the ear canal prophylactically to avoid wax impaction.

Despite being a benign condition, left neglected, $\mathrm{KO}$ can result in extensive bone resorption with the involvement of vital intratemporal soft tissue structures. Erosion of the labyrinth with resultant lateral semicircular canal fistula, erosion of the dural plate, the temporomandibular joint, and facial nerve palsy, although rare, have been described in the literature (5). Facial nerve palsy associated with $\mathrm{KO}$ is a dreaded complication. To date, a total of five cases of $\mathrm{KO}$ complicated with facial nerve palsy have been reported (5-9). A PubMed search revealed four such reported cases, either as isolated case reports or as a part of case series $(5,6,8,9)$. Further google scholar search revealed one more case (7).

Most of the patients were adults, belonging to an age group range higher than that generally described for KO. The youngest patient was 22 years old. Three patients were males and two were females. Two of the patients had a history of bronchiectasis. The duration of facial palsy varied from a few days to a few weeks. Two patients had House-Brackmann grade III facial palsy, while one patient had complete facial palsy. Recovery of facial nerve functioning was complete or near complete, however, this parameter was not available for the patient with the pre-operative complete facial palsy. Intraoperatively, a variety of findings were encountered, including exposed mastoid segment of the facial nerve, auto-mastoidectomy, EAC granulation and aural polyp. One patient had retracted tympanic membrane and eroded long process of incus. The patient with auto-mastoidectomy had extensive bony remodeling including temporomandibular joint erosion and eroded roof of the jugular bulb. Interestingly, two of the patients with facial nerve palsy were found to have erosion/ inflammatory changes involving the horizontal segment of the facial nerve that was discovered either on pre-operative computerized tomography scan or during intraoperative exploration.

\section{Conclusion}

Keratosis obturans is a benign but painful condition characterized by altered EAC epithelium migratory properties. Facial nerve palsy and erosion of vital intratemporal structures can occur as a result of pressure erosion of the bony EAC and adjacent structures. The present case highlights the smoldering nature of $\mathrm{KO}$ and a need for timely intervention.

Informed Consent: Written informed consent was obtained from the patient who participated in this study.

Peer-review: Externally peer-reviewed.

Author Contributions: Concept - A.S., M.H., K.K.H.; Design - A.S.; Supervision - K.K.H.; Resource - A.S., M.H., K.K.H.; Materials - A.S., M.H., K.K.H.; Data Collection and/or Processing - A.S.; Analysis and/ or Interpretation - A.S., M.H., K.K.H.; Literature Search - A.S., M.H.; Writing - A.S., M.H., K.K.H.; Critical Reviews - A.S., M.H., K.K.H.

Conflict of Interest: The authors have no conflicts of interest to declare.

Financial Disclosure: The authors declared that this study has received no financial support.

\section{References}

1. Toynbee J. Specimens of molluscum contagiosum developed in the external auditory meatus. Lond Med Gazzette 1850: 46: 811.

2. Piepergerdes JC, Kramer BC, Behnke EE. Keratosis obturans and external auditory canal cholesteatoma. Laryngoscope 1980; 90: 383-91. [CrossRef]

3. Hawke M, Shanker L. Automastoidectomy caused by keratosis obturans: a case report. J Otolaryngol 1986; 15: 348-50.

4. Bunting W. Ear canal cholesteatoma and bone absorption. Trans Am Acad Opthalmol Otolaryngol 1968; 72: 161-72.

5. Saunders NC, Malhotra R, Biggs N, Fagan PA. Complications of keratosis obturans. J Laryngol Otol 2006; 120: 740-4. [CrossRef]

6. Glynn F, Keogh IJ, Burns H. Neglected keratosis obturans causing facial nerve palsy. J Laryngol Otol 2006; 120: 784-5. [CrossRef]

7. Menon UK, Deepthi NV. Facial palsy of unusual etiology - A diagnostic dilemma. Indian J Otol 2011; 17: 37-9. [CrossRef]

8. Shinnabe A, Hara M, Hasegawa M, Matsuzawa S, Kanazawa H, Yoshida N, et al. A comparison of patterns of disease extension in keratosis obturans and external auditory canal cholesteatoma. Otol Neurotol 2013; 34: 91-4. [CrossRef]

9. Saniasiaya J, Nik Othman NA, Mohamad Pakarul Razy NH. Keratosis obturans complicated with facial nerve palsy: a diagnostic dilemma. Braz J Otorhinolaryngol 2016. 2016 May 24. doi: 10.1016/j.bjorl.2016.04.012. [Epub ahead of print] [CrossRef] 